\title{
Research on Logistics Informatization and Construction of Logistics Information Platform
}

\author{
Dapeng Ren \\ Xi'an Eurasia University, Xi’an, Shaanxi, 710065
}

Keywords: logistics; logistics information; logistics information platform

\begin{abstract}
With the development of Internet technology, the level of logistics information has been improved, and strengthening the construction of logistics information platform is beneficial to improve the efficiency and economic benefit of logistics enterprises. This paper first describes the connotation of logistics information and logistics information platform, then analyzes the necessity and importance of logistics information and logistics information platform construction, and then analyzes the main functions of logistics information platform. Finally, the paper tries to explore the logistics information platform construction ideas.
\end{abstract}

\section{Introduction}

With the development of the Internet and the maturity of the application of logistics information technology, the construction of logistics information platform has become an important trend in the development of logistics industry. Enterprises can make a positive response to the market and guide enterprises to adjust their business activities, to realize industry resource sharing, and the rapid, accurate and real-time flow of information in the logistics system give play to the overall advantage of regional logistics through the construction of logistics information platform

\section{The connotation of logistics informatization and logistics information platform}

\subsection{The connotation of logistics informatization}

Logistics informatization refers to a series of processing activities, such as collecting, classifying, transferring, collecting, identifying, and tracking and querying all or part of the information generated in the process of logistics by modern information technology. To achieve the control of the flow of goods, thus reducing costs and improving efficiency of management activities. Logistics informatization is the soul of modern logistics and the inevitable requirement and cornerstone of modern logistics development.

\subsection{The connotation of logistics information platform}

It is generally believed that any website that can support or exchange information between supply and demand of logistics services can be regarded as a logistics information platform. For example, a logistics company designed an information exchange system to facilitate the contact between the company and its users, so that the user and the company can maintain a convenient contact, then the system has the nature of the logistics information platform. A professional logistics information service website is a typical logistics information platform.

3. The necessity and importance of logistics informatization and logistics information platform construction

\subsection{The necessity of logistics informatization and logistics information platform construction}

Logistics information plays a very important role in logistics activities. The collection, transmission, storage, processing and output of logistics information through the logistics information platform become the basis for decision-making and command and coordination of the 
whole logistics activities. Modern logistics urgently needs to use information technology to integrate the existing resources such as logistics, commercial flow, capital flow, information flow and so on, so as to improve the rationality of the allocation of the whole resources. The primary significance of the construction of logistics information platform is to improve the efficiency of logistics participants, and then to promote the efficiency of the whole social work. High-quality logistics information platform also means that the demand side of logistics services can enjoy faster and cheaper logistics services, improve their work efficiency or quality of life. The development of logistics public information platform, especially the third party logistics public information platform, will be of great significance when the development of logistics industry lags behind in China. The internal logistics of enterprises has low information level and poor information communication, which results in large inventory and waste of transportation capacity, which requires the construction of logistics information platform.

\subsection{The importance of logistics informatization and logistics information platform}

The most important role of the logistics information platform is to integrate the information resources of each logistics information system, complete the data exchange between the systems, and realize the information sharing. The logistics information platform can handle the transfer function of public information in the information system. Each subsystem that undertakes data collection sends public data to the information platform according to certain rules, and stores it after standardized processing by the information platform. According to the requirement planning or the request of each logistics information system, the data is sent out in the standard format. Through logistics information platform, the cooperation between logistics enterprises and upstream and downstream enterprises can be strengthened, and supply chain can be formed and optimized. When cooperative enterprises request logistics, logistics enterprises can quickly establish supply links through logistics information platform to provide related logistics services. This will help to improve the utilization rate of a large number of idle logistics resources in society, play an important role in readjusting, allocating the logistics resources of the society, optimizing the social supply chain, and straightening out the economic chain, which will not only produce very good economic benefits, And will have very good social benefits. Logistics information platforms such as Shanghai, Shenzhen and Tianjin provide vehicle owners and cargo owners with the function of loading and unloading vehicles, thus effectively utilizing empty car resources. The construction of logistics information platform is propitious to realize the docking with BTOB or BTOC system of e-commerce. Any kind of transaction takes the transfer of goods or the provision of service as the ultimate goal. Electronic commerce is a mode of transaction, of course, it is no exception. With the development of e-commerce transaction system, how to configure the electronic logistics system has become a key problem, and the logistics information platform is a better solution to this problem. Through the construction of logistics information platform, it can provide good logistics service for electronic commerce and promote the development of electronic commerce. The general logistics information platform all provides the online transaction function; this actually provides the electronic commerce basic function.

\section{The Main functions of logistics information platform}

The main function of logistics information platform includes two parts: basic function and extended function.

\subsection{The basic functions of logistics information platform}

Data exchange function, which is the core function of the information platform, mainly refers to the translation, conversion and communication of electronic documents, including online customs declaration, license application, settlement, payment (refund) tax, The exchange of information between customers and businesses and other users connected to the information platform. In the data exchange function, there is also a very important function-card management function. Certificate management is the document information generated by the user on the information 
platform plus additional information, according to a certain format saved in the form of documents, in case of future business disputes inquiry, proof of the use; information release service function, this function is realized in the form of Web site. As long as the enterprise connects to the information platform Web site through Internet, it can obtain the logistics information provided on the site. This type of information mainly includes water, land transport prices, news and announcements, government guides, cargo sources and capacity, flight schedules, empty stowage, railway trips, cargo sources, union members, vocational training, policies and regulations, etc.; member service functions, Personalized service for registered members. It mainly includes member document management, member's cargo status and position tracking, transaction statistics, member credit evaluation, etc.; online trading function, trading system provides a virtual trading market for suppliers and buyers. Both sides can publish and query the information of supply and demand, the information of their own interest can be further discussed with the publisher and the transaction system can make deals for both parties.

\subsection{The extended functionality of logistics information platform}

The function of intelligent distribution makes use of transportation resources of logistics center, supply information of merchants and shopping information of consumers to optimize distribution, so that the cost of distribution is the lowest, and the goods are delivered within the time required by users. The common solution is to set up a mathematical model, and the decision scheme is given by the computer using mathematical programming method, and then the managers choose according to the actual situation. The typical problems to be solved in intelligent distribution include route selection, delivery order, distribution vehicle type, delivery time limited by customers, and cargo tracking function. GPS/GIS system is used to track the status and location of goods. The status and location data are stored in the database, and the user can obtain trace information through Call Center or Web site. Inventory management function, which is using logistics information platform to integrate the whole supply chain, so that the inventory can achieve the minimum inventory to meet the customer' service conditions. The acquisition of the lowest stock requires the accumulation and analysis of a large amount of historical data. The comprehensive factors such as customer service level, inventory cost, transportation cost and so on should be considered in order to minimize the total cost. Typical problems that can be solved include: the number of products to be produced in the next production cycle; the optimal quantity of supplementary goods; and the minimum inventory point (safe inventory) for replenished goods. Decision analysis function, which is to establish logistics business mathematical model, through the analysis of existing data, help managers to identify, evaluate and compare the logistics strategy and strategy options; financial services function, which is financial services such as insurance, banking, taxation, foreign exchange and so on can be realized through the network of logistics information platform after the establishment of relevant laws and regulations and the further improvement of network security technology. The information platform plays the role of information transmission in this kind of business,, the specific business is dealt with in the relevant department, and the result is returned to the customer through the information platform.

\section{Paths on the construction of logistics information platform}

\subsection{To strengthen logistics overall planning}

As a part of large logistics planning, the construction of logistics information platform should be carried out under the guidance of the overall logistics planning strategy. It should conform to the objectives and principles of logistics planning and serve the logistics planning, so that the effect of logistics planning can really play out. Logistics information platform should be unified planning, unified leadership, make full use of existing social information resources, avoid duplication of construction. At the same time the implementation process should be in accordance with the actual situation step by step, pay attention to practical results with steady progress. 


\subsection{Government-driven, third-party implementation, market-oriented operation}

The construction of logistics information platform involves different management departments, all kinds of logistics enterprises and the supply and demand of goods, to deal with all aspects of the relationship, need to be coordinated and promoted by the government. Logistics information platform needs to adopt the principle of third party implementation to ensure the independence of the platform so that it can provide an orderly competitive environment on the basis of fairness, openness and fairness. In order to meet the vast number of customers on the logistics information platform service function requirements. The management of logistics information platform should implement market operation. In order to arouse the enthusiasm of the main operators, we can adopt the way of holding shares by the main operators, and carry out the risk mortgage, so as to link the business performance with the interests of the operators, and increase the operation vitality of the entities.

\subsection{To speed up the Construction of logistics information standardization}

At present, the logistics information system of most enterprises is still closed, and the information is exchanged according to the common standard protocol in the internal network. In order to exchange data between different logistics information systems, the logistics information platform needs standardized logistics information to realize the smooth data exchange of different logistics information systems. If the logistics information data is not standardized, standardized and unified, it is bound to increase the difficulty of data exchange, reduce the utilization efficiency of logistics information platform, cause waste of resources and information distortion, so we must speed up the construction of logistics information standardization in China.

\subsection{Formulation of policies, regulations and supporting measures}

Logistics information platform will occur in the course of operation, such as document charges, member rights and obligations, management, backup proof and so on. This needs to formulate a set of corresponding laws and regulations to regulate. In addition, the supporting measures to promote the development of logistics information platform are also necessary, such as: preferential policies for the introduction of talents, preferential tax policies, and preferential policies for land use, preferential policies for communication charges, and so on.

\subsection{To speed up the cultivation of logistics information talents}

The construction of logistics information platform needs professional logistics information talents, so it is necessary to speed up the cultivation of logistics information talents. It is necessary to establish an effective talent introduction mechanism and reward mechanism for outstanding personnel, and strengthen the training of internal personnel logistics information technology. At the same time, we should actively cooperate with social education institutions, increase investment in training logistics information talents, train different levels of talents through various ways, and introduce high-quality logistics information management personnel from abroad if necessary.

\section{Conclusion}

All in all, the development of informationization can save cost and improve benefit for logistics enterprises. Logistics enterprises need to speed up the construction of informatization, build logistics information platform, realize information exchange, information service and resource sharing among enterprises, to realize the sustainable development of logistics enterprises.

\section{References}

[1] Ke Wang. Discussion on the Construction of GIS Logistics Information Management Platform [J]. Journal of Shandong Agricultural University (Natural Science Edition), 2018 (3): 500-503

[2] Jitao Yang, Jin Wang. Study on Dalian’s Integration into "Belt and Road" Construction Logistics 
Field-Analysis Based on Logistics Informatization [J]. China Economic and Trade Guide (Theoretical Edition), 2018 (2): 50-51

[3] Zhongxu Jin, Yuexian Guo. Research on the Logistics Mode of Vehicle-Free Carrier Based on Internet [J]. Journal of Shijiazhuang Railway University (Social Sciences Edition), 2017,11 (2): 6-11.

[4] Xia Wu. Research on the Development Path of Vehicle-Free Carrier Based on Internet-Taking Yiyuntong as an example [J]. Science and Technology Entrepreneurship monthly, 2017,30 (10): 42-43.

[5] Shengqi Cheng. Analysis of Logistics Business Model Based on Internet-A Case Study of Car-free carrier [J]. Commercial Economy Research, 2018 (11): 103-105

[6] Hansong Zhao. Research on the Feasibility of Logistics Information Platform [J]. Consumer Guide, 2018 (11). 